\title{
Functional cell surface expression of Toll-like receptor 9 promotes cell proliferation and survival in human hepatocellular carcinomas
}

\author{
JUNICHIRO TANAKA ${ }^{1}$, KAZUSHI SUGIMOTO ${ }^{1}$, KATSUYA SHIRAKI ${ }^{1}$, MASAHIKO TAMEDA ${ }^{1}$, \\ SATOKO KUSAGAWA ${ }^{1}$, KEIICHIRO NOJIRI ${ }^{1}$, TETSUYA BEPPU ${ }^{1}$, KENTARO YONEDA ${ }^{1}$, \\ NORIHIKO YAMAMOTO ${ }^{1}$, KAZUHIKO UCHIDA ${ }^{2}$, TAKAHIRO KOJIMA ${ }^{2}$ and YOSHIYUKI TAKEI $^{1}$ \\ ${ }^{1}$ Department of Gastroenterology, Mie Graduate University School of Medicine, 2-174, Edobashi, Tsu, \\ Mie 514-8507; ${ }^{2}$ Graduate School of Comprehensive Human Sciences, University of Tsukuba, \\ 1-1-1 Tennoudai, Tsukuba, Ibaraki 305-0006, Japan
}

Received February 9, 2010; Accepted April 19, 2010

DOI: 10.3892/ijo_00000730

\begin{abstract}
Toll-like receptor 9 (TLR9) is a pattern-recognition receptor that is involved in immune signaling and plays a crucial role in cell survival through recognition of various bacterial and viral components including unmethylated CpGDNA. TLR9 expression and function in cancer cells are not well understood. We investigated the expression of TLR9, and the function of TLR9 signaling, in hepatocellular carcinoma (HCC) cells following stimulation with CpG-oligodeoxynucleotides (ODNs). Positive immunohistochemical staining for TLR9 was observed in $85.7 \%$ of HCC tissues. Western blot analysis revealed that TLR9 was expressed both on the cell membrane and in the cytoplasm of HCC cell lines. Full-length TLR9 was predominantly expressed on the membrane rather than in the cytoplasm, whereas multiple cleaved forms of TLR9 were predominantly expressed in the cytoplasm rather than on the membrane. Cell surface stimulation of TLR9 promoted cell proliferation, and, furthermore, the TLR9 agonists, CpG-ODNs, reduced the cytotoxicity of the anti-cancer drug adriamycin (ADM) via upregulation of apoptosis inhibitors such as survivin, $\mathrm{Bcl}-\mathrm{xL}$, XIAP and cFLIP, in HCC cell lines. Although cell surface stimulation of TLR9 did not activate either the NF-кB signaling pathway or the type-I IFN secretion pathway, gene chip microarray analysis indicated that TLR9 agonists closely regulated multiple oncology-related genes and transcription factors involved in tumorigenesis and cancer progression. In conclusion, our results indicate that functional cell surface expression of TLR9 in human HCC may play an important role in tumorigenesis and cancer progression.
\end{abstract}

Correspondence to: Dr Katsuya Shiraki, Department of Gastroenterology, Mie University School of Medicine, 2-174 Edobashi, Tsu, Mie 514-8507, Japan

E-mail: katsuyas@clin.medic.mie-u.ac.jp

Key words: Toll-like receptor, hepatocellular carcinomas

\section{Introduction}

Toll-like receptors (TLRs) are involved in innate immunity against microbial pathogens such as bacteria, protozoa, fungi or viruses. In mammals, the TLR family is currently known to consist of 11 members, which exhibit specificity for pathogen-derived ligands. These receptors are type I transmembrane proteins and play a critical role in the subsequent induction of adaptive immune responses (1-5). Stimulation of TLRs can induce a range of innate and adaptive immune responses through cytokines, interferons, chemokines and cell surface molecules, as well as increase cellular effector functions.

TLRs are broadly distributed in various cell types of the immune system, including polymorphonuclear phagocytes, monocytes, dendritic cells and natural killer cells, as well as in some epithelial and endothelial cells (6-9). However, to date, the specific subcellular localization of TLRs remains to be determined. TLR1, 2, 4, 5 and 6 are present in the plasma membrane whereas TLR3, 7, 8 and 9 are postulated to be present in endosomes. All TLRs are most likely involved in signal pathways (10). Via the TLR signaling pathways, the liver is continuously exposed to a large variety of antigens, such as dietary antigens, bacterial toxins and several proinflammatory cytokines through TLR signaling (11). Hepatocytes express low levels of TLR2 and 4, which are responsive to lipopolysaccharide (LPS). Kupffer cells, as well as hepatic stellate cells, biliary epithelial cells and sinusoidal endothelial cells, which express TLR4, produce several proinflammatory cytokines in response to LPS (11-13). In humans, TLR9 is expressed in B-lymphocytes, monocytes and plasmacytoid dendritic cells. TLR9 recognizes specific oligodeoxynucleotide (ODN) sequences consisting of unmethylated CpG-ODNs, which are frequently present in bacterial and viral DNA (14). It has recently been reported that treatment of chronic hepatitis C infection with the TLR9 agonist CpG 10101, a synthetic ODN, is associated with dose-dependent increases in markers of immune activation (interferon (IFN)- $\gamma$-inducible protein 10 (IP-10), IFN- $\alpha$ and 2'5'-oligoadenylate synthetase $(\mathrm{OAS})$ ) and with a decrease in HCV-RNA levels (15). 
However, the exact mechanism responsible for the expression and function of TLR9 in liver diseases has yet to be fully elucidated.

Besides TLR expression in immune cells, recent evidence suggests that functional TLRs are also expressed by a wide variety of cancer cells $(16,17)$, and that TLR signaling may contribute to tumor cell proliferation, survival and chemosensitivity (18-20). In particular, the expression of TLR9 has been detected in various normal epithelial and cancer cells, including breast, brain, lung, gastric and prostate cancers (21-25). These data suggest that functional TLR9 signaling in tumor cells is associated with the progression of cancer and the evasion of host defenses. However, little is known regarding the significance of TLR9 in human hepatocellular carcinoma (HCC) cells.

We therefore investigated the expression and role of TLR9 in HCC cells and tissues by examination of the function of the TLR9 signaling which occurs after stimulation of HCC cells with CpG-ODNs. Surprisingly, we found TLR9 was expressed not only in the cytoplasm, but also on the membrane, and that TLR9 signaling pathway promotes the proliferation and survival of HCC cells.

\section{Materials and methods}

Cells and HCC tissues. The human HCC cell lines HepG2 (JCRB 1054), HLE (JCRB 0404) and Huh7 (JCRB 0403) were purchased from the Human Science Research Resource Bank (Osaka, Japan). The human HCC cell lines SK-Hep1 and the colon adenocarcinoma cells Colo 320 were purchased from the American Type Culture Collection (Rockville, MD). All cells were cultured in DMEM at $37^{\circ} \mathrm{C}$, supplemented with $1 \%$ penicillin/streptomycin (Gibco BRL, Grand Island, NY) and $10 \%$ heat-inactivated fetal calf serum (Gibco BRL).

A total of 42 HCC tissues (9 non-tumor tissues, which included 4 from patients with cirrhotic liver and 5 from patients with chronic hepatitis, and 8 tissues with metastasis from HCC tissues) were obtained from tissue array slides (SuperBioChips Laboratories, Seoul, Korea). We obtained informed consent from all patients prior to the subsequent use of their resected tissues. Resected tissues were frozen immediately at $-80^{\circ} \mathrm{C}$ or were fixed in $10 \%$ formalin.

Reagents. The type C CpG oligonucleotide (ODN M362: 5'tcg tcg tcg ttc gaa cga cgt tga t-3') used as a human TLR9 ligand, and the control, non-stimulatory oligonucleotide ODN M362 (ODN M362 Control: 5'-tgc tgc tgc ttg caa gca gct tga t-3'), were purchased from InvivoGen (San Diego, CA). Cisplatin (CDDP) was purchased from Sigma (St. Louis, MO). Adriamycin (ADM) was purchased from Wako (Osaka, Japan), and Lipofectamine LTX (Lipo) was purchased from Invitrogen (Carlsbad, CA).

Flow cytometric analysis. Non-permeabilized live HCC cell lines which had been cultured for $48 \mathrm{~h}$, were washed with PBS and then incubated with FITC-anti-TLR9 antibody (Imgenex, San Diego, CA) or control IgG1. Cells were analyzed by FACScan using CellQuest software (BectonDickinson, Tokyo, Japan).
Immunohistochemical staining. Immunohistochemical staining of TLR9 was performed on HCC- and non-HCC-tissues using a labeled streptavidin-biotin method. Deparaffinized sections were heated for $5 \mathrm{~min}$ at $120^{\circ} \mathrm{C}$ in a pressure cooker to reactivate the antigen. Sections were blocked and incubated with an anti-TLR9 antibody (Imgenex) overnight at $4{ }^{\circ} \mathrm{C}$. Sections were then incubated with a second biotinylated antibody, followed by the avidin-biotin-peroxidase complex. The peroxidase signal was then developed in a substrate solution of $0.01 \% 3$ 3'-diaminobenzidene-hydrogen peroxidase and the tissue was counterstained with $10 \%$ hematoxylin.

Cell proliferation assay. HCC cells were seeded at a density of $1.0 \times 10^{4}$ cells/well in 96-well flat-bottom microtiter plates (Corning Glass Works, Corning, NY) and were incubated at $37^{\circ} \mathrm{C}$ in $5 \% \mathrm{CO}_{2}$. After incubation for $24 \mathrm{~h}$, various reagents were added, and the plates were incubated for $48 \mathrm{~h}$. To assess the viability of HCC cells, a 3-(4,5-dimethylthiazol-2-yl)-2,5diphenyl tetrazolium bromide (MTT) assay was performed using a Cell Titer 96-assay kit (Promega, Madison, WI) according to the manufacturer's instructions.

Immunoblotting. The expression of TLR9, and the loading control $\alpha$-tubulin, in colon adenocarcinoma cell line (Colo 320) and in human HCC cell lines (SK-Hep1, HepG2, HLE, Huh7) was analyzed by immunoblotting. Briefly, after incubation on 6-well plates (Nunc ${ }^{\mathrm{TM}}$ Brand Products, Denmark) for $48 \mathrm{~h}$, these cells were washed twice with phosphate-buffered saline (PBS) and were then lysed by the addition of SDS sample buffer (50 mmol/1 Tris-HCl, pH 6.8, 2.5\% SDS, 5\% glycerol, $5 \%$ 2-mercaptoethanol and $0.01 \%$ bromophenol blue). Equal amounts of extracted proteins were separated by SDS-PAGE and were then transferred to PVDF membranes (Millipore, Billerica, MA). Blots were blocked by incubation in Tris- $\mathrm{HCl}$ (pH 7.5) containing 5\% milk and $0.1 \%$ Tween-20 for $30 \mathrm{~min}$ at room temperature, and were probed overnight at $4^{\circ} \mathrm{C}$ with primary antibodies. The following primary antibodies were used: anti-TLR9 monoclonal antibody (Imgenex), anti- $\alpha$ tubulin monoclonal antibody (Oncogene Research Products, San Diego, CA). Antibodies were diluted in $5 \%$ milk or in BSA in Tris- $\mathrm{HCl}$ ( $\mathrm{pH} 7.5$ ) containing $0.1 \%$ Tween-20. Immunoblots were then probed with horseradish peroxidaseconjugated anti-mouse immunoglobulin G (IgG) (diluted $1: 1000$ in $1 \%$ milk or in BSA in Tris-HCl, pH 7.5) (Amersham Biosciences, Buckinghamshire, UK). After the final wash, signals were detected using an ECL kit (Amersham Pharmacia Biotech, Buckinghamshire, UK).

To elucidate the subcellular localization of TLR9 in HepG2 cells, cell lysates were separated into cytosolic (F1), membrane/ organelle (F2), nuclear (F3) and cytoskeletal matrix (F4) protein fractions using a ProteoExtract ${ }^{\mathrm{TM}}$ Subcellular Proteome Extraction kit (Merck KGaA, Darmstadt, Germany) according to the manufacturer's instructions. The expression of calpain and pan-cadherin were also assayed as markers of cytosolic and membrane/organelle fractions. The following primary antibodies were used: anti-TLR9 monoclonal antibody (Imgenex), anti-calpain monoclonal antibody (Calbiochem, San Diego, CA) and anti-pan cadherin monoclonal antibody (Sigma).

The expression of apoptosis inhibitors (survivin, XIAP, cFLIP and Bcl-xL) in HCC cell lines was also analyzed by 
immunoblotting. After stimulation of HCC cells for $48 \mathrm{~h}$ with $1 \mu \mathrm{M} \mathrm{CpG}, 1 \mu \mathrm{g} / \mathrm{ml} \mathrm{ADM}$ or $1 \mu \mathrm{M} \mathrm{CpG}+1 \mu \mathrm{g} / \mathrm{ml} \mathrm{ADM}$ cell lysates were separated by SDS-PAGE and were transferred to nitrocellulose membranes. Immunoblots were probed with anti-survivin monoclonal antibody (Santa Cruz Biotechnology, Inc., Santa Cruz, CA), anti-cFLIP polyclonal antibody (MBL, Nagoya, Japan), anti-hILP/XIAP monoclonal antibody, anti-Bcl-xL polyclonal antibody (both from Transduction Laboratories, Lexington, KY) and anti- $\alpha$-tubulin monoclonal antibody (Oncogene Research Products). Immunoblots were then probed with horseradish peroxidase-conjugated antimouse IgG or horseradish peroxidase-conjugated anti-rabbit IgG (Amersham Biosciences).

$N F-\kappa B$ activity assays and expression analysis of IRF-7. The $\mathrm{NF}-\kappa \mathrm{B}$ activity assay was performed using the Dual-Glo ${ }^{\mathrm{TM}}$ Luciferase Assay System (Promega) and the pGL4.32 (luc2P/ NF- $\mathrm{B}-\mathrm{RE} / \mathrm{Hygro}$ ) Vector (Promega) according to the manufacturer's instructions.

The expression of interferon regulatory factor 7 (IRF-7) in CpG-stimulated or non-stimulated, HCC cells was analyzed by immunoblotting using an anti-IRF-7 antibody (Abnova, Taipei, Taiwan).

RNA extraction and oligonucleotide microarray. Gene expression profiles were examined to determine the effects of stimulation of TLR9 with its agonist CpG-ODNs on gene expression in HCC cell lines. Briefly, HepG2 and Huh7 cells were incubated without stimulation, or with $1 \mu \mathrm{M} \mathrm{CpG} \mathrm{ODNs,} \mathrm{for}$ 48 h. Total RNA was extracted from both CpG-stimulated and non-stimulated HCC cells using TRIzol reagent (Invitrogen) according to the manufacturer's instructions. RNA integrity and purity were verified using the Agilent Bioanalyzer 2100 (Agilent Technologies, Rockville, MD). Total RNA (10 $\mu \mathrm{g})$ was reverse transcribed into single-stranded cDNA, which was then converted to double-stranded cDNA. The doublestranded cDNA was extracted using the GeneChip Sample Cleanup Module (Qiagen, Hilden, Germany). To synthesize biotinylated cRNA, the purified cDNA was used as a template in an in vitro transcription reaction using the Enzo BioArray HighYield RNA Transcript Labeling kit (Enzo Life Science, Farmingdale, NY). The biotinylated target cRNA was purified using the GeneChip Sample Cleanup Module (Qiagen). The purified biotinylated cRNA $(20 \mu \mathrm{g})$ was then fragmented. The hybridization cocktail consisted of $15 \mu \mathrm{g}$ of fragmented biotin-labeled cRNA spiked with a eukaryotic hybridization control. This hybridization cocktail $(200 \mu \mathrm{l})$ was directly loaded onto the human Gene 1.0 ST Array (Affymetrix, Santa Clara, CA) and was then hybridized at $45^{\circ} \mathrm{C}$ for $16 \mathrm{~h}$, with rotation at $60 \mathrm{rpm}$ using a rotisserie motor. After hybridization, the array was washed, stained with streptavidin phycoerythrin using the Affymetrix GeneChip Fluidics Workstation 450, and was scanned on an Affymetrix GeneChip Scanner 3000 . The preparation of cRNA, hybridization and scanning of the microarrays were carried out according to the manufacturer's protocols.

Microarray data analysis. The Affymetrix Microarray Suite 5.1 program was used to monitor specific hybridization to the microarray and to monitor gene expression. Data from
A

TLR9

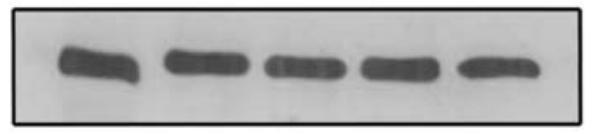

$\alpha$-tubulin
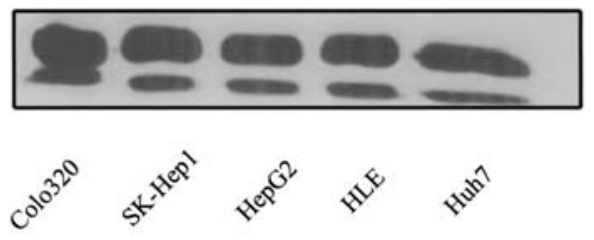

B

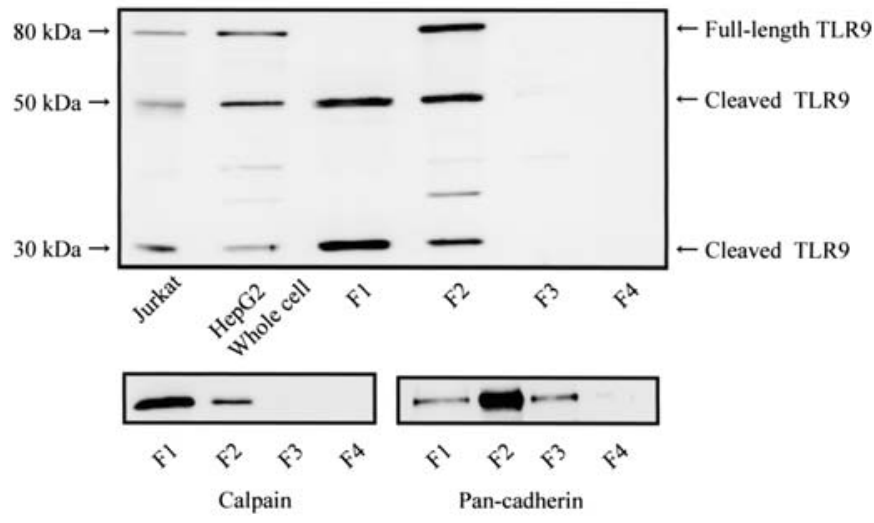

Figure 1. Western blot analysis of TLR9 expression in cancer cells and in subcellular fractions. (A) Western blot analysis of TLR9, and the loading control $\alpha$-tubulin, in colon adenocarcinoma cells (Colo 320) and in human HCC cells (SK-Hep1, HepG2, HLE, Huh7). Cell lysates were separated by SDS-PAGE and were transferred to nitrocellulose prior to blotting. (B) Western blot analysis of TLR9 in subcellular fractions of HepG2 cells. Cell lysates were analyzed by Western blotting for TLR9 expression prior to, and following, separation of the lysate into cytosolic (F1), membrane/organelle $(\mathrm{F} 2)$, nuclear $(\mathrm{F} 3)$ and cytoskeletal matrix (F4) protein fractions using a ProteoExtract ${ }^{\mathrm{TM}}$ Subcellular Proteome Extraction kit. The expression of TLR9 on Jurkat cells was assayed as a positive control. Western blots of calpain and pan-cadherin, markers of cytosolic and membrane/organelle fractions respectively, were also shown. Full-length TLR9 was preferentially expressed in the membrane fraction rather than in the cytoplasm. In contrast, multiple cleaved forms of TLR9 were preferentially expressed in the cytoplasmic rather than in the membrane fraction. Cell lysates were separated by SDS-PAGE followed by transfer to nitrocellulose prior to blotting.

individual arrays were analyzed using GeneSpring software (Silicon Genetics, Redwood City, CA), which was used to identify genes uniquely up- or down-regulated at single or multiple time-points. Clustering by QT-Clust algorithm, and calculation of significant functional genes, were also performed using this software.

\section{Results}

TLR9 is expressed on both the cell membrane and in the cytoplasm of HCC cell lines and liver tissues. TLR9 protein expression levels were analyzed by Western blot analysis in cell lysates of cancer cell lines. As shown in Fig. 1A, TLR9 was detected in all HCC cell lines and in colonic adenocarcinoma cells, indicating a high prevalence of TLR9 expression in human HCC. Additionally, TLR9 was expressed not only in the cytoplasm, but also on the membrane of HepG2 cells. Full-length TLR9 was predominantly expressed on the 


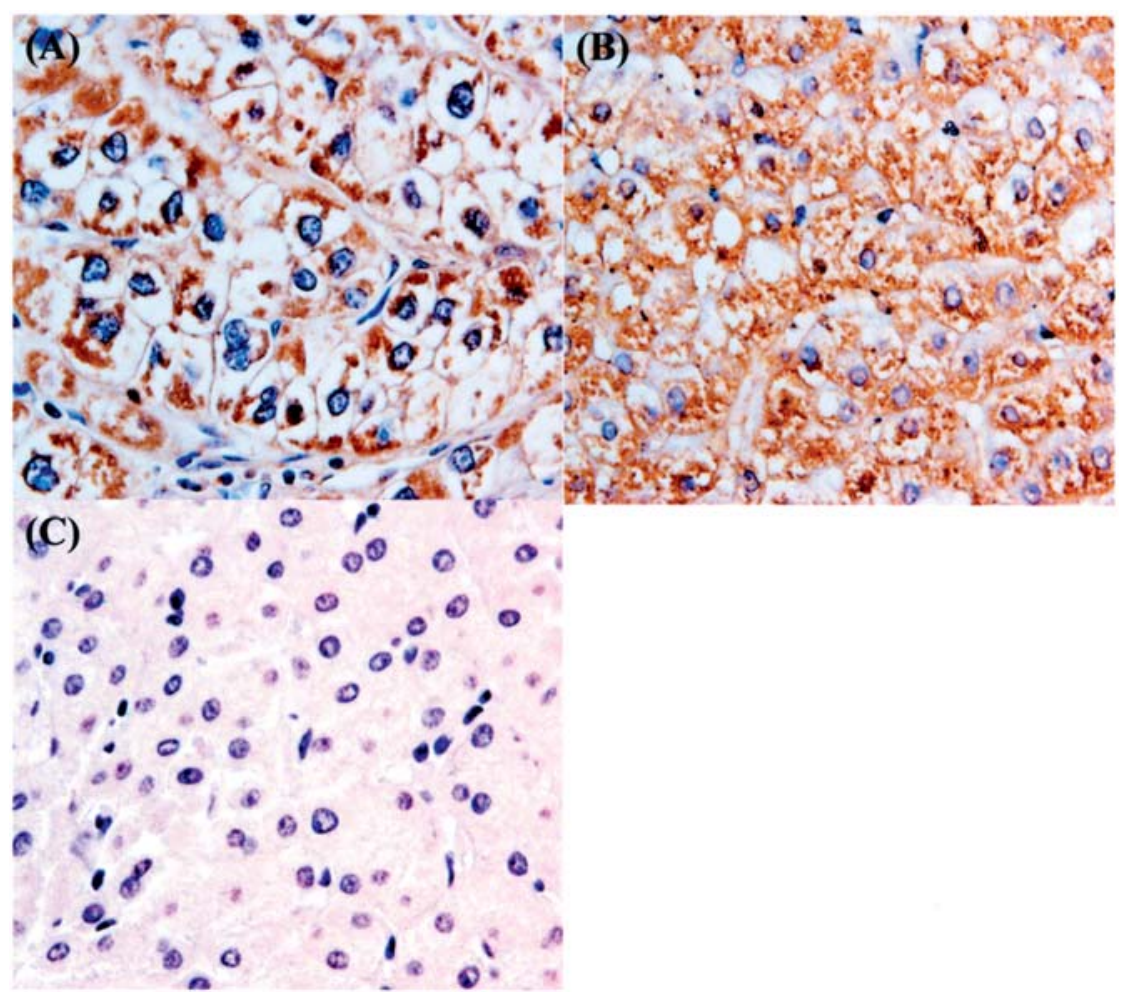

Figure 2. Immunohistochemical analysis of TLR9 expression in human tissue. Immunohistochemical staining of a human HCC (A) and non-HCC (B) tissue specimen using an anti-TLR9 antibody, and control immunohistochemical staining of a human HCC specimen (C) using an iso-type matched mouse IgG. Staining was carried out using a labeled streptavidin-biotin method. Note TLR9 staining is observed not only in the cytoplasm, but also in the membrane (original magnification, $\mathrm{x} 400$ ).

Table I. Expression of TLR9 in HCC and non-tumor tissues.

\begin{tabular}{lcrc}
\hline & & & Staining \\
\cline { 3 - 4 } Histology & No or weak $(\%)$ & Moderate $(\%)$ & Strong $(\%)$ \\
\hline Non-tumor tissues & $2(22.2)$ & $6(66.7)$ & $1(11.1)$ \\
HCC & & & $3(37.5)$ \\
Poorly differentiated & $1(12.5)$ & $14(60.9)$ & $9(21.7)$ \\
Moderately differentiated & $4(17.4)$ & $3(42.9)$ & $3(42.9)$ \\
Well differentiated & $1(14.3)$ & $6(75.0)$ & $1(12.5)$ \\
Metastasis from HCC & $1(12.5)$ &
\end{tabular}

membrane rather than in the cytoplasm. In contrast, multiple cleaved forms of TLR9 were predominantly expressed in the cytoplasm rather than on the membrane in the absence of stimulation with CpG-ODNs (Fig. 1B).

TLR9 expression was further investigated in liver tissue by immunohistochemical staining of both non-HCC and HCC lesions (Fig. 2). While in 36 of $42 \mathrm{HCC}$ cases (85.7\%) there was clear TLR9 positivity, no significant differences were observed between different histological grades. TLR9 staining was detected not only in the cytoplasm, but also on the membrane. Few differences were noted in the TLR9 staining patterns between non-tumor and tumor tissues. In metastases from HCC, 7 of 8 cases (87.5\%) showed TLR9 positivity (Table I).
Since TLR9 receptor localization depends upon cell type, we further investigated the cell surface expression of TLR9 in HCC cells using flow cytometric analysis. As shown in Fig. 3, significant detectable surface staining of TLR9 was observed in all HCC cell lines tested. These results suggest that TLR9 is frequently expressed not only in the cytoplasm, but also on the membrane, of both normal and cancerous liver cells.

CpG-ODNs affect cell proliferation. In order to determine the biological significance of the signaling that occurs via the cell surface TLR9 in HCC cells, we investigated the cytotoxicity of cell treatment with the TLR9 ligand CpG-ODNs. As shown in Fig. 4A, stimulation with CpG-ODNs for $48 \mathrm{~h}$ 


\section{HepG2}

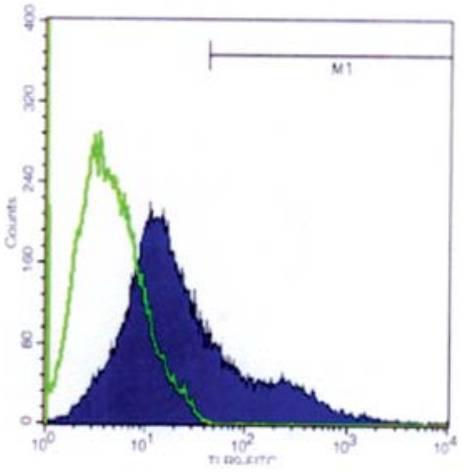

SK-Hep1

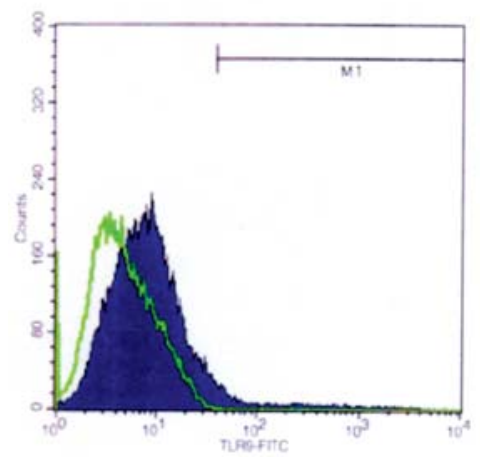

HLE

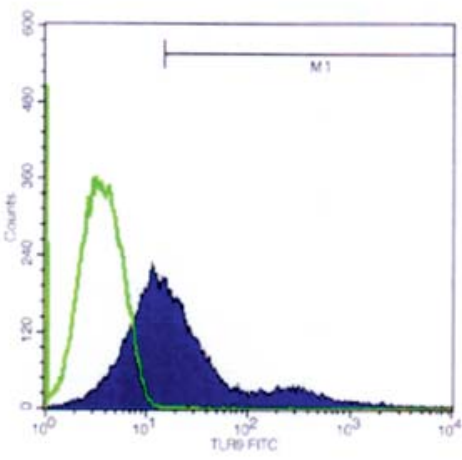

Huh7

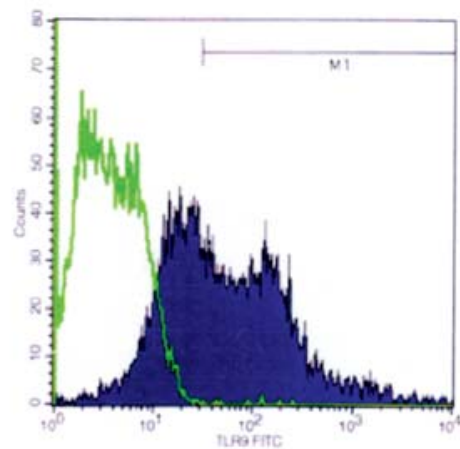

Figure 3. Cell surface expression of TLR9 in HCC cell lines. The cell surface expression of TLR9 in the HCC cell lines SK-Hep1, HepG2, Huh7 and HLE, was assayed by incubation of the cells for $48 \mathrm{~h}$ followed by FACS analysis using a FITC-anti-TLR9 antibody. Autofluorescence was determined using cells incubated with control, FITC-mouse IgG1 (green lines).

increased the cell viability of Huh7 and SK-Hep1 cells in a dose-dependent manner. We next determined the biological significance of the signaling that occurs via the cytoplasmic TLR9 in HCC cells, by investigation of the cytotoxicity of transfected CpG-ODNs. As shown in Fig. 4B, stimulation with transfected CpG-ODNs, which stimulates intracellular TLR9 receptors, did not affect cell viability compared to stimulation with non-stimulatory oligonucleotides (control oligo). These results suggest that cell surface stimulation with CpG-ODNs might affect cell proliferation and survival in HCC cells.

$C p G-O D N s$ reduce the cytotoxicity of $A D M$ via up-regulation of apoptosis inhibitors in HCC cells. We next examined possible interactions between the effect of CpG-ODNs and that of the anti-cancer reagents, adriamycin (ADM) or cisplatin (CDDP), on the viability of HCC cell lines. Cell surface stimulation of HepG2 cells with a combination of $1 \mu \mathrm{M}$ CpG-ODNs and a subtoxic level of ADM for $48 \mathrm{~h}$ resulted in an increase in cell viability of about $56 \%$ compared to stimulation with ADM alone. Similarly, in Huh7 cells, cell surface stimulation with a combination of $1 \mu \mathrm{M} \mathrm{CpG-ODNs} \mathrm{and} \mathrm{a}$ subtoxic level of ADM for $48 \mathrm{~h}$ resulted in an increase in cell viability of about $69 \%$ compared to stimulation with ADM alone (Fig. 5A). In contrast, intracellular TLR9 stimulation with a combination of transfected $\mathrm{CpG}-\mathrm{ODNs}$ and a subtoxic level of ADM for $48 \mathrm{~h}$ did not increase the cell viability compared to stimulation with ADM alone (Fig. 5B). To investigate the molecular mechanisms underlying the observed increase in cell viability which occurred following cell surface stimulation with $1 \mu \mathrm{M}$ CpG-ODNs and a subtoxic level of $\mathrm{ADM}$, we analyzed the expression of apoptosis inhibitors by immunoblotting analysis (Fig. 5C). Stimulation with $1 \mu \mathrm{g} / \mathrm{ml}$ ADM down-regulated the expression levels of survivin, Bcl-xL, XIAP and cFLIP, whereas stimulation with $1 \mu \mathrm{g} / \mathrm{ml}$ $\mathrm{ADM}$ in combination with $1 \mu \mathrm{M}$ CpG-ODNs significantly inhibited the ADM-mediated down-regulation of the expression levels of these proteins. These results suggest that CpGODNs might contribute to a reduction in the cytotoxicity of $\mathrm{ADM}$ via up-regulation of apoptosis inhibitors in HepG2 cells.

$C p G-O D N s$ do not activate either the $N F-\kappa B$ signaling pathway or the type I-IFN secretion pathway. We further examined TLR9-mediated induction of $\mathrm{NF}_{-} \mathrm{\kappa B}$ and type I IFNs, since TLR9 signaling is known to modulate these signaling pathways. Induction of $\mathrm{NF}-\kappa \mathrm{B}$ activity following cell surface stimulation with or without $\mathrm{CpG-ODNs}$ was assayed using a luciferase reporter assay. No significant differences were noted in NF- $\mathrm{KB}$ activity between the CpGstimulated and $\mathrm{CpG}$-unstimulated group (data not shown). Regulation of the expression level of interferon regulatory factor 7 (IRF-7), by cell surface stimulation with or without $1 \mu \mathrm{M}$ CpG-ODNs, was assayed using immunoblotting. However, the expression levels of IRF-7 were also not increased by treatment with or without $1 \mu \mathrm{M}$ CpG-ODNs in 
A

HepG2

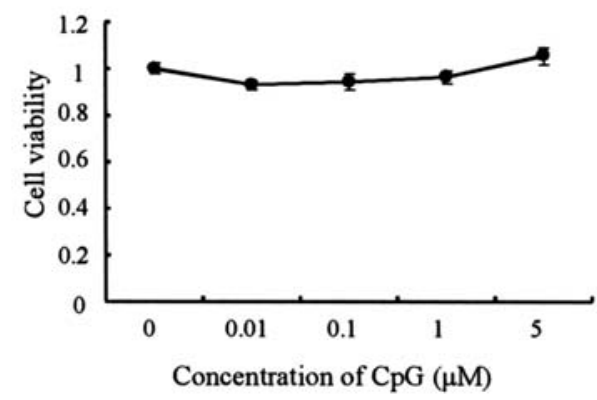

SK-Hep1

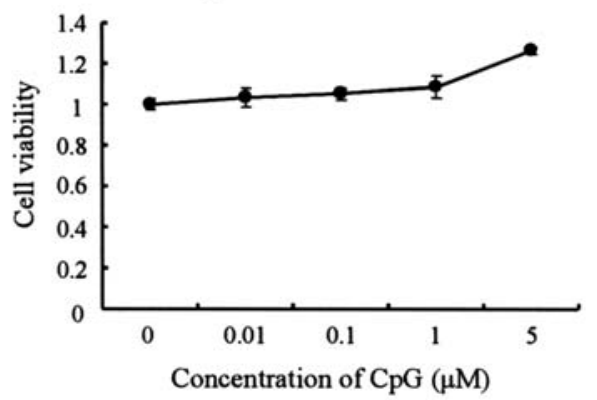

Huh7

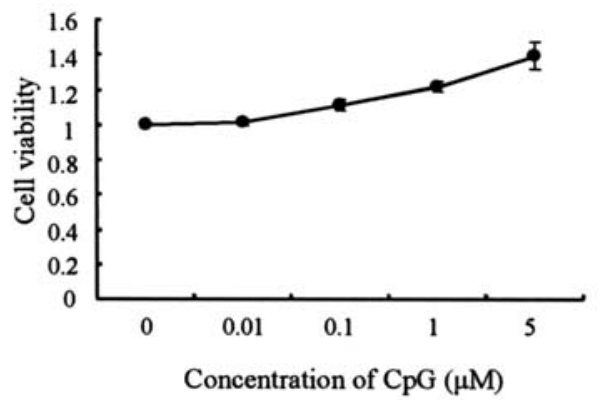

HLE

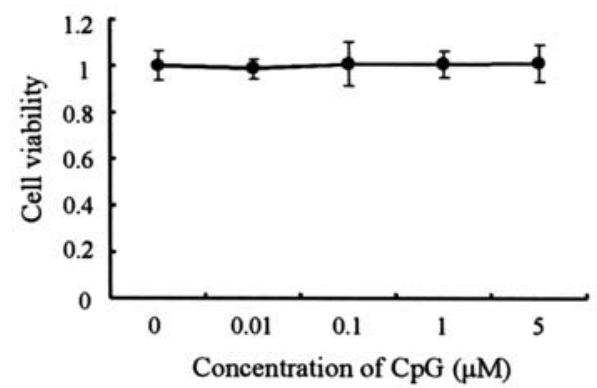

B

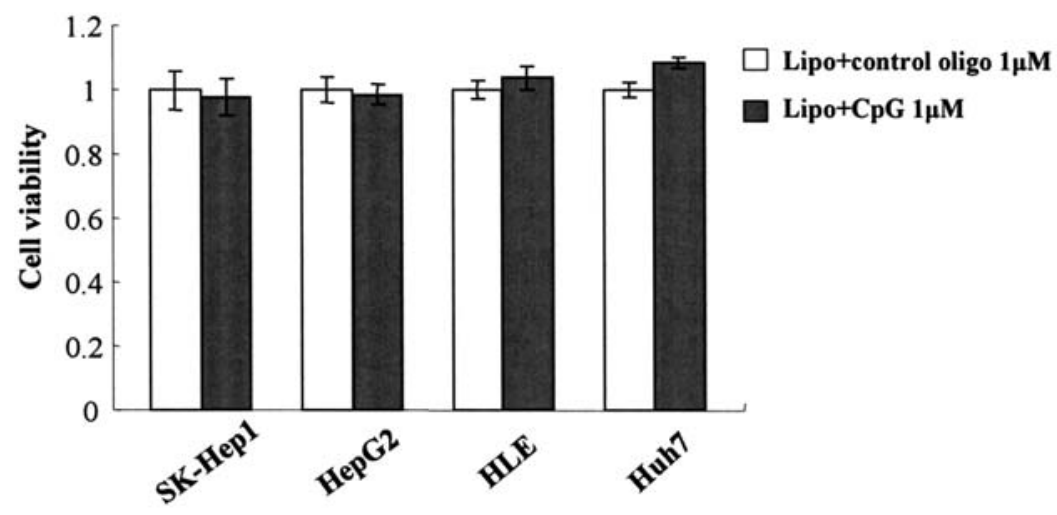

Figure 4. Effects of $\mathrm{CpG}$ on HCC cell viability. (A) Effect of exogenous $\mathrm{CpG}$ on $\mathrm{HCC}$ cell viability. The indicated HCC cells were incubated with various concentrations of $\mathrm{CpG}$ for $48 \mathrm{~h}$ following which, cell viability was assessed using the MTT assay in which cell viability in the absence of treatment was set at 1 . Data shown are the means \pm SD of six independent experiments. (B) Effect of transfected CpG on HCC cell viability. The indicated HCC cells were incubated with $2.5 \mu \mathrm{l} / \mathrm{ml}$ Lipofectamine LTX $+1 \mu \mathrm{M}$ of a non-stimulatory oligonucleotide (control oligo; open columns) or $+1 \mu \mathrm{M}$ CpG (closed columns) for $48 \mathrm{~h}$. Cell viability was assessed using the MTT assay in which viability of the cells transfected with the control oligo was set at 1 . Data shown are the means \pm SD of six independent experiments.

HCC cell lines (data not shown). These results indicate that cell surface stimulation with $\mathrm{CpG}-\mathrm{ODN}$ did not activate either the NF-кB signaling pathway or the type I-IFN secretion pathway.

$C p G-O D N$ regulates multiple oncology-related genes. In order to determine potential signaling events underlying the effect of CpG-ODNs on HCC cell proliferation and survival, we investigated gene regulation following cell surface $\mathrm{CpG}$ ODN-treatment of HepG2 and Huh7 cells using GeneChip microarray analysis. Several oncology-related genes and transcription factors, which were up- or down-regulated by cell surface CpG-ODN-treatment, were identified as shown in Tables II and III. These genes included SNRPN, SMG1, MALAT1, SETBPI and NDRG that are considered to be closely related with oncogenesis and tumor progression. The
GRAP (GRB2-related adaptor protein) gene is also known to be regulated by oncogenic signaling (26). We found that the gene Kruppel-like factor 5 (KLF5), was the most highly down-regulated gene. KLF5 is a member of the kruppel $\mathrm{C} 2 \mathrm{H} 2-$ type zinc-finger protein family which contains three $\mathrm{C} 2 \mathrm{H} 2$ type zinc fingers. The expression of KLF5 in TLR9-stimulated cells was reduced to about $50 \%$ of that in non-treated cells. The mRNA levels of the genes GDF5OS, ANKRD20B and ANKRD6 were also reduced by TLR9 stimulation to about $70 \%$ of the levels in non-stimulated cells.

\section{Discussion}

In an earlier study, we demonstrated for the first time that several TLRs, including TLR9, are expressed in human HCC tissues (27). TLRs are known to be expressed by various 
A
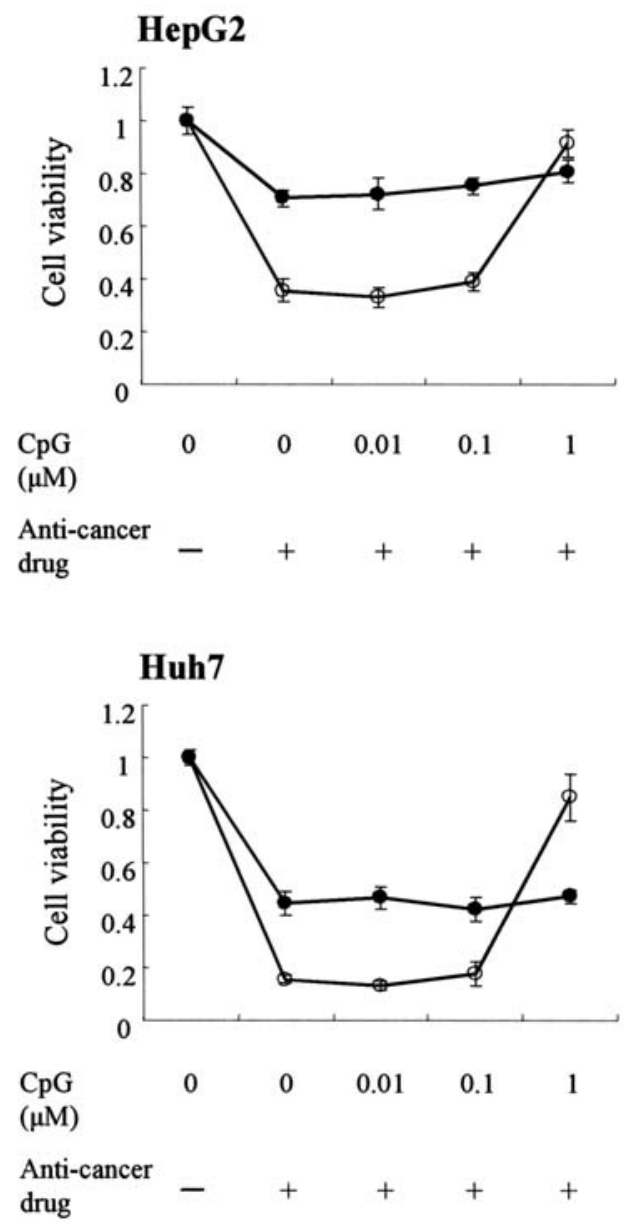

C

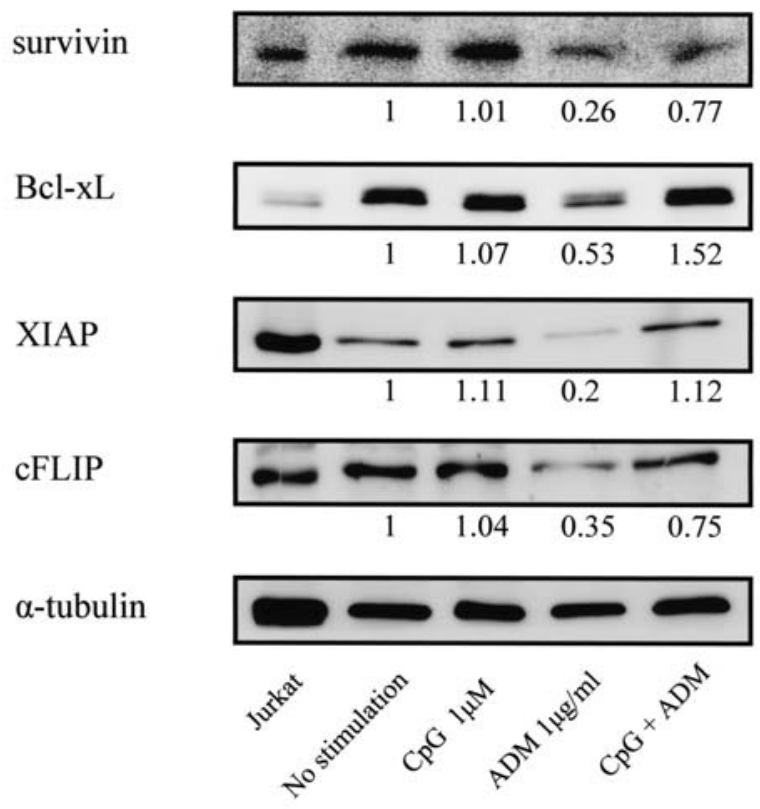

immune cells, as well as by non-immune cells (1-4). Furthermore, TLRs, including TLR9, are expressed by a wide variety of cancer cells $(16,17,21-25)$ and may contribute to tumor cell proliferation, survival and chemosensitivity (18-20). These data suggest that TLR9 signaling in tumor cells is associated with the progression of cancer and the evasion of host defenses. However, little is known regarding
B
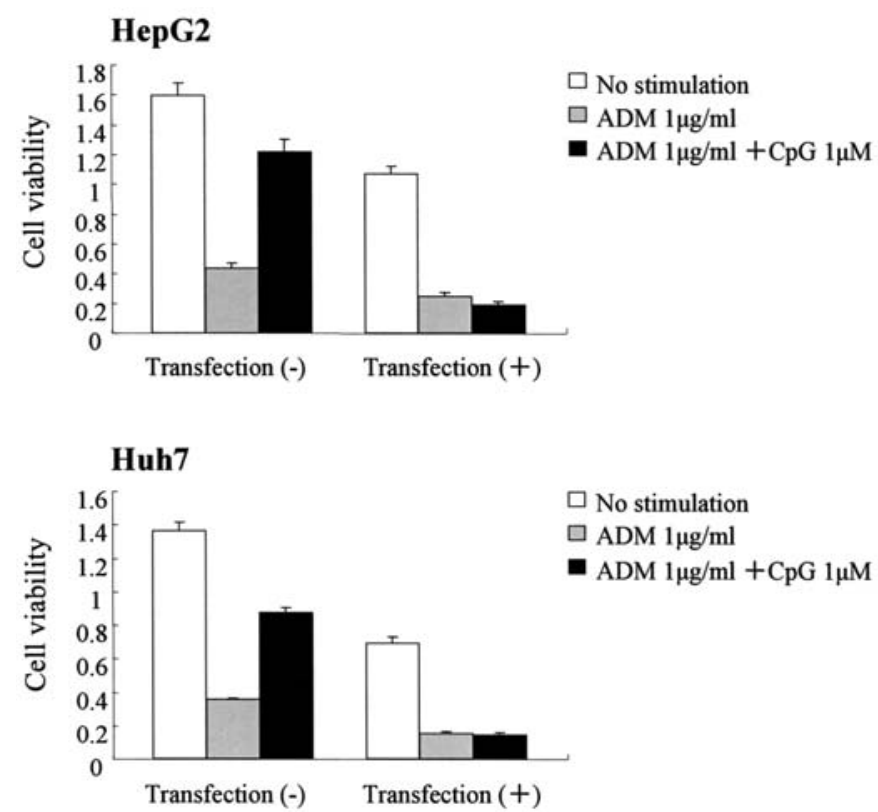

Figure 5. CpG modulation of the effect of anti-cancer agents on HCC cell viability. (A) Effect of $\mathrm{CpG}$ in combination with anti-cancer reagents on HCC cell viability. The HCC cells HepG2 and Huh7 were incubated with various concentration of $\mathrm{CpG}$ together with $1 \mu \mathrm{g} / \mathrm{ml}$ adriamycin (ADM, open circles), or with $50 \mu \mathrm{g} / \mathrm{ml}$ cisplatin (CDDP, closed circles) for $48 \mathrm{~h}$ following which, cell viability was assessed using the MTT assay in which viability in the absence of treatment was set at 1 . Data shown are the means $\pm \mathrm{SD}$ of six independent experiments. (B) Effect of $\mathrm{CpG}$ transfection into HCC cells on ADM-modulation of cell viability. The HCC cells HepG2 and Huh7 were incubated in the absence of stimulation (open columns) or in the presence of $1 \mu \mathrm{g} / \mathrm{ml}$ ADM (gray columns) or $1 \mu \mathrm{M} \mathrm{CpG}$ and $1 \mu \mathrm{g} / \mathrm{ml}$ ADM (closed columns) for $48 \mathrm{~h}$ following which, cell viability was assessed using the MTT assay. Data shown are the means \pm SD of six independent experiments. (C) Effect of $\mathrm{CpG}$, with or without ADM, on the expression of apoptosis inhibitors in HCC cells. The expression of the indicated apoptosis inhibitors in cell lysates of non-stimulated Jurkat cells (positive control) or in HepG2 cells following no stimulation, or following stimulation with $1 \mu \mathrm{M}$ $\mathrm{CpG}, 1 \mu \mathrm{g} / \mathrm{ml} \mathrm{ADM}$, or with $1 \mu \mathrm{M} \mathrm{CpG}$ and $1 \mu \mathrm{g} / \mathrm{ml} \mathrm{ADM}$, was analyzed by SDS-PAGE and immunoblotting. The expression of $\alpha$-tubulin was also assayed as a loading control. Protein expression was quantified using densitometry and expression levels relative to those in non-stimulated cells are indicated below each blot. Stimulation with $1 \mu \mathrm{M} \mathrm{CpG}$ and $1 \mu \mathrm{g} / \mathrm{ml}$ ADM up-regulated the expression of apoptosis inhibitors compared to stimulation with $1 \mu \mathrm{g} / \mathrm{ml}$ ADM alone.

the significance of TLR9 for the function of human HCC cells. We therefore attempted to elucidate the functional significance of TLR9 expression in HCC cells and tissues.

The immunohistochemical analysis of the present study revealed that, in addition to non-tumor tissues such as cirrhotic or normal tissues, $85.7 \%$ of HCC tissues expressed TLR9. We also detected the TLR9 protein in a panel of HCC 
Table II. Oncology-related genes regulated by TLR9 in HepG2 cells.

\begin{tabular}{|c|c|c|c|c|}
\hline Gene ID & $\begin{array}{l}\text { Gene } \\
\text { symbol }\end{array}$ & Gene name & $\begin{array}{l}\text { Change in } \\
\text { Log } 2 \text { ratio }\end{array}$ & $\begin{array}{l}\text { Fold } \\
\text { change }\end{array}$ \\
\hline \multicolumn{5}{|c|}{$\begin{array}{l}\text { Up-regulated } \\
\text { oncology-related } \\
\text { genes }\end{array}$} \\
\hline BC010353 & PTPLA & $\begin{array}{l}\text { Protein tyrosine phosphatase-like (proline instead } \\
\text { of catalytic arginine), member A }\end{array}$ & 0.71 & 1.63 \\
\hline- & $\begin{array}{l}\text { SNRPN/ } \\
\text { SNORD116-2 }\end{array}$ & $\begin{array}{l}\text { Small nuclear ribonucleoprotein polypeptide N/ } \\
\text { Small nuclear RNA, C/D box 116-2 }\end{array}$ & 0.57 & 1.48 \\
\hline U47077 & PRKDC & Protein kinase, DNA-activated, catalytic polypeptide & 0.56 & 1.48 \\
\hline DQ097177 & HUWE1 & HECT, UBA and WWE domain containing 1 & 0.56 & 1.47 \\
\hline AF395444 & SMG1 & PI-3-kinase-related kinase SMG-1 & 0.54 & 1.45 \\
\hline- & MALAT1 & $\begin{array}{l}\text { Metastasis associated lung adenocarcinoma } \\
\text { transcript } 1 \text { (non-protein coding) }\end{array}$ & 0.52 & 1.43 \\
\hline AF265555 & BIRC6 & Baculoviral IAP repeat-containing 6 (apollon) & 0.51 & 1.43 \\
\hline U79716 & RELN & Reelin & 0.51 & 1.42 \\
\hline \multicolumn{5}{|c|}{$\begin{array}{l}\text { Down-regulated } \\
\text { oncology-related } \\
\text { genes }\end{array}$} \\
\hline AF132818 & KLF5 & Kruppel-like factor 5 (intestinal) & -0.93 & 0.52 \\
\hline ВC085019 & GDF5OS & Growth differentiation factor 5 opposite strand & -0.50 & 0.71 \\
\hline- & $\begin{array}{l}\text { ANKRD20B/ } \\
\text { CCDC29 }\end{array}$ & $\begin{array}{l}\text { Ankyrin repeat domain 20B/ } \\
\text { Coiled-coil domain containing } 29\end{array}$ & -0.46 & 0.73 \\
\hline ВC042173 & ANKRD6 & Ankyrin repeat domain 6 & -0.45 & 0.73 \\
\hline
\end{tabular}

Table III. Oncology-related genes regulated by TLR9 in Huh7 cells.

\begin{tabular}{|c|c|c|c|c|}
\hline Gene ID & $\begin{array}{c}\text { Gene } \\
\text { symbol }\end{array}$ & Gene name & $\begin{array}{l}\text { Change in } \\
\text { Log2 ratio }\end{array}$ & $\begin{array}{c}\text { Fold } \\
\text { change }\end{array}$ \\
\hline \multicolumn{5}{|c|}{$\begin{array}{l}\text { Up-regulated } \\
\text { oncology-related } \\
\text { genes }\end{array}$} \\
\hline U05569 & CRYAA & Crystallin, alpha A & 0.77 & 1.71 \\
\hline BC035856 & GRAP & GRB2-related adaptor protein & 0.70 & 1.62 \\
\hline AY189690 & NXN & Nucleoredoxin & 0.62 & 1.54 \\
\hline BC146776 & SETBP1 & SET-binding protein 1 & 0.59 & 1.51 \\
\hline AF495523 & REX01L1 & REX1, RNA exonuclease 1 homolog (S.cerevisiae)-like 1 & 0.55 & 1.46 \\
\hline AF287261 & SETD8 & SET domain containing (lysine methyltransferase) 8 & 0.55 & 1.46 \\
\hline AF040962 & PSPN & Persephin & 0.54 & 1.46 \\
\hline AB021172 & NDRG4 & NDRG family member 4 & 0.54 & 1.45 \\
\hline \multicolumn{5}{|c|}{$\begin{array}{l}\text { Down-regulated } \\
\text { oncology-related } \\
\text { genes }\end{array}$} \\
\hline- & SCARNA7 & Small Cajal body-specific RNA 7 & -0.72 & 0.61 \\
\hline BC002673 & HSPB8 & Heat shock $22 \mathrm{kDa}$ protein 8 & -0.57 & 0.67 \\
\hline
\end{tabular}

cell lines by Western blot analysis. Thus, our results indicate that there is high expression of TLR9 in human HCC.

In the present study, the results of Western blot analysis of subcellular fractions, and flow cytometric analysis of intact cells, revealed that TLR9 is clearly expressed on both the cell surface and in the cytoplasm of human HCC cells. TLR1, 2, 4, 5, 6 and 10 are usually reported as being expressed on the cell surface, while TLR3, 7, 8 and 9, which can recognize 
nucleic acid ligands, are usually expressed in the endosomes and the endoplasmic reticulum. Specifically, TLR9 has been localized to the endoplasmic reticulum(ER) together with another ER-resident protein, UNC93B1. Following stimulation with CpG-DNA, TLR9 is translocated to the endosomal/ lysosomal compartment in an UNC93B1-dependent manner, thereby allowing recruitment of the adaptor molecule, MyD88, and subsequent signaling (28-30). The localization of TLR9 both at the membrane and in intracellular compartments suggested the possibility that TLR9 may induce different signals at each location. Indeed we have previously demonstrated that functional TLR3 is expressed on both the cell surface and in the cytoplasm of HCC cells, and that intracellular TLR3 signaling is involved in cell death, while, in contrast, cell surface TLR3 signaling is responsible for activation of NF- $\mathrm{KB}$ (27). In the present study, stimulation of cell surface TLR9 promotes cellular proliferation and survival. However, direct stimulation of intracellular, cleaved, TLR9 had little effect on cell proliferation and apoptosis. In addition, full-length TLR9 is predominantly expressed on the membrane rather than in the cytoplasm. In contrast, multiple cleaved forms of TLR9 are predominantly expressed in the cytoplasm rather than on the membrane in the absence of CpG-ODN stimulation. It has been recently demonstrated in macrophages that, after stimulation, TLR9 is cleaved into a C-terminal fragment and that this cleaved form alone, translocated to the endosomal/lysosomal compartment, is competent for MyD88-dependent signaling (31). Although the real significance of the subcellular localization of TLR9 in human HCC cells remains uncertain, our findings strongly suggest that HCC cells may be able to respond to various nucleic acids using both the cell surface and endosomal TLR9. Therefore, further study will be needed to clarify the molecular function and regulation of endosomal TLR9.

We next attempted to elucidate the biological significance of the functional TLR9 signaling in HCC cells. In lung cancer cells, stimulation of TLR9 with its agonists $\mathrm{CpG}-\mathrm{ODNs}$ promotes a reduction in tumor necrosis factor (TNF)- $\alpha$ induced apoptosis (23). The present study is the first report that cell surface stimulation with $\mathrm{CpG}-\mathrm{ODNs}$ contributes to enhanced cell proliferation and survival in HCC cells. However this result is consistent with the fact that $\mathrm{CpG-ODNs}$ induce cancer cell proliferation via secretion of IL-10 which is also related to induction/enhancement of tumor angiogenesis (32).

This study also suggested that cell surface CpG-ODNs stimulation reduced toxicity of ADM via up-regulation of apoptosis inhibitor proteins. Thus, although subtoxic levels of ADM decreased cell viability, cell surface stimulation with a combination of $\mathrm{CpG}-\mathrm{ODN}$ and $\mathrm{ADM}$ resulted in an increase in cell viability. By Western blot analysis, we found that cell surface stimulation with ADM down-regulated the expression levels of apoptosis inhibitors such as survivin, Bcl-xL, XIAP and cFLIP, but surprisingly, cell surface stimulation with a combination of $\mathrm{CpG}-\mathrm{ODN}$ s and ADM significantly inhibited the ADM-mediated down-regulation of the expression levels of these proteins. These results suggest that cell surface stimulation with CpG-ODNs might contribute to a reduction in the cytotoxicity of ADM towards HepG2 cells via up-regulation of apoptosis inhibitors.
Engagement of the TLR9 signaling pathway leads to the activation of two major transcription factors that have central roles in innate immunity, i.e., NF-кB and IRF-7. TLR9 requires the adaptor molecule MyD88 for initiation of these signals, and MyD88 can directly associate with and activate IRF-7, leading to type I-IFN production $(33,34)$. Additionally, the MyD88-dependent signaling pathway leads to NF- $\mathrm{KB}$ nuclear translocation and activation of NF-кB-dependent genes via an interaction between IRAK1 and TRAF6 $(2,35)$. NF-кB usually plays an important role in regulating immune and inflammatory responses, apoptosis and oncogenes (36-38). In

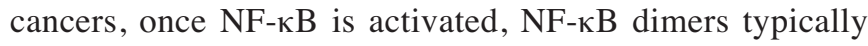
enter the nucleus and induce the expression of cytokines, growth factors and anti-apoptotic proteins. However, activation of these signals by cell surface TLR9 was not detected in the present study, suggesting that cell surface TLR9 signaling in HCC cells may modulate a novel, MyD88-independent signaling pathway for the TLR9-dependent cancer progression.

To investigate which signals may play a role in this proposed novel signaling pathway, we carried out a microarray analysis of genes regulated by CpG-ODN in HepG2 cells. This microarray analysis found that $\mathrm{CpG-ODNs} \mathrm{regu-}$ lated multiple oncology-related genes known to be involved in oncogene-signaling, cell proliferation and anti-apoptosis. For example, the metastasis associated lung adenocarcinoma transcript 1 (MALAT1) gene was up-regulated in HepG2 cells stimulated with CpG-ODNs. This gene is associated with increased risk of metastasis and poorer prognosis in nonsmall cell lung cancer (39). MALAT1 has also been shown to be overexpressed in hepatocellular carcinoma and, more broadly, 50-80\% of cases of colon, lung, pancreas and breast cancer that were analyzed exhibited significantly increased in situ hybridization intensity for MALAT1 compared with the surrounding normal tissues $(40,41)$. Conversely, KLF5 is down-regulated by $\mathrm{CpG}-\mathrm{ODN}$ treatment and down-regulation of KLF5 may be an early event in intestinal tumorigenesis. Although expression of KLF5 in non-transformed intestinal epithelial cells enhances cell growth, KLF5 expression in colon cancer cell lines inhibits cell growth (42). Also, ankyrin repeat domains regulate apoptosis through interaction with p53, and its family members play a role in cytokine signaling and hepatocarcinogenesis (43). These findings suggest that TLR9 agonists closely regulated oncogenic genes, which may contribute towards tumorigenesis and cancer progression.

In conclusion, TLR9 is expressed on both the cell surface and in the cytoplasm of HCC cells. Cell surface TLR9 signaling may promote the proliferation and survival of HCC cells by a novel, MyD88-independent signaling pathway. Furthermore, TLR9 agonists closely regulated the expression of oncogenic genes, which may contribute towards tumorigenesis and cancer progression.

The current findings may help to define clinical perspectives for inhibition of cell surface TLR9 agonists which can regulate cell proliferation and survival of HCC cells. Further evaluation of the potential physiological roles, and the type of regulation associated with TLR9, needs to be undertaken.

\section{References}

1. Takeda K, Kaisho T and Akira S: Toll-like receptors. Annu Rev Immunol 21: 335-376, 2003. 
2. Takeda $\mathrm{K}$ and Akira S: Toll-like receptors in innate immunity. Int Immunol 17: 1-14, 2005.

3. Beutler B, Jiang Z, Georgel P, Crozat K, Croker B, Rutschmann S, Du X and Hoebe K: Genetic analysis of host resistance: Toll-like receptor signaling and immunity at large. Annu Rev Immunol 24: 353-389, 2006.

4. Kopp E and Medzhitov R: Recognition of microbial infection by Toll-like receptors. Curr Opin Immunol 15: 396-401, 2003.

5. Akira S, Uematsu S and Takeuchi O: Pathogen recognition and innate immunity. Cell 124: 783-801, 2006.

6. Becker MN, Diamond G, Verghese MW and Randell SH: CD14-dependent lipopolysaccharide-induced beta-defensin-2 expression in human tracheobronchial epithelium. J Biol Chem 275: 29731-29736, 2000.

7. Muzio M, Bosisio D, Polentarutti N, D'Amico G, Stoppacciaro A Mancinelli R, van't Veer C, Penton-Rol G, Ruco LP, Allavena P and Mantovani A: Differential expression and regulation of tolllike receptors (TLR) in human leukocytes: selective expression of TLR3 in dendritic cells. J Immunol 164: 5998-6004, 2000.

8. Faure E, Thomas L, Xu H, Medvedev A, Equils O and Arditi M: Bacterial lipopolysaccharide and IFN-gamma induce Toll-like receptor 2 and Toll-like receptor 4 expression in human endothelial cells: role of NF-kappa B activation. J Immunol 166: 2018-2024, 2001.

9. Visintin A, Mazzoni A, Spitzer JH, Wyllie DH, Dower SK and Segal DM: Regulation of Toll-like receptors in human monocytes and dendritic cells. J Immunol 166: 249-255, 2001.

10. Barton GM, Kagan JC and Medzhitov R: Intracellular localization of Toll-like receptor 9 prevents recognition of selfDNA but facilitates access to viral DNA. Nat Immunol 7: 49-56, 2006.

11. Matsumura T, Degawa T, Takii T, Hayashi H, Okamoto T, Inoue J and Onozaki K: TRAF6-NF-kappaB pathway is essential for interleukin-1-induced TLR2 expression and its functional response to TLR2 ligand in murine hepatocytes. Immunology 109: 127-136, 2003.

12. Harada K, Ohira S, Isse K, Ozaki S, Zen Y, Sato Y and Nakanuma Y: Lipopolysaccharide activates nuclear factorkappaB through toll-like receptors and related molecules in cultured biliary epithelial cells. Lab Invest 83: 1657-1667, 2003.

13. Uhrig A, Banafsche R, Kremer M, Hegenbarth S, Hamann A, Neurath M, Gerken G, Limmer A and Knolle PA: Development and functional consequences of LPS tolerance in sinusoidal endothelial cells of the liver. J Leukoc Biol 77: 626-633, 2005

14. Bauer S, Kirschning CJ, Häcker H, Redecke V, Hausmann S, Akira S, Wagner $\mathrm{H}$ and Lipford GB: Human TLR9 confers responsiveness to bacterial DNA via species-specific CpG motif recognition. Proc Natl Acad Sci USA 98: 9237-9242, 2001

15. McHutchison JG, Bacon BR, Gordon SC, Lawitz E, Shiffman M, Afdhal NH, Jacobson IM, Muir A, Al-Adhami M, Morris ML, Lekstrom-Himes JA, Efler SM and Davis HL: Phase 1B, randomized, double-blind, dose-escalation trial of $\mathrm{CpG} 10101$ in patients with chronic hepatitis C virus. Hepatology 46: 1341-1349, 2007.

16. Chen R, Alvero AB, Silasi DA, Steffensen KD and Mor G: Cancers take their Toll-the function and regulation of Toll-like receptors in cancer cells. Oncogene 27: 225-233, 2008.

17. Huang B, Zhao J, Unkeless JC, Feng ZH and Xiong H: TLR signaling by tumor and immune cells: a double-edged sword. Oncogene 27: 218-224, 2008

18. Salaun B, Coste I, Rissoan MC, Lebecque SJ and Renno T: TLR3 can directly trigger apoptosis in human cancer cells. J Immunol 176: 4894-4901, 2006.

19. Kelly MG, Alvero AB, Chen R, Silasi DA, Abrahams VM, Chan S, Visintin I, Rutherford T and Mor G: TLR-4 signaling promotes tumor growth and paclitaxel chemoresistance in ovarian cancer. Cancer Res 66: 3859-3868, 2006

20. Huang B, Zhao J, Li H, He KL, Chen Y, Chen SH, Mayer L, Unkeless JC and Xiong H: Toll-like receptors on tumor cells facilitate evasion of immune surveillance. Cancer Res 65: 5009-5014, 2005.

21. Merrell MA, Ilvesaro JM, Lehtonen N, Sorsa T, Gehrs B, Rosenthal E, Chen D, Shackley B, Harris KW and Selander KS: Toll-like receptor 9 agonists promote cellular invasion by increasing matrix metalloproteinase activity. Mol Cancer Res 4: 437-447, 2006

22. El Andaloussi A, Sonabend AM, Han Y and Lesniak MS: Stimulation of TLR9 with CpG ODN enhances apoptosis of glioma and prolongs the survival of mice with experimental brain tumors. Glia 54: 526-535, 2006.
23. Droemann D, Albrecht D, Gerdes J, Ulmer AJ, Branscheid D, Vollmer E, Dalhoff K, Zabel P and Goldmann T: Human lung cancer cells express functionally active Toll-like receptor 9 . Respir Res 6: 1, 2005.

24. Schmausser B, Andrulis M, Endrich S, Müller-Hermelink HK and Eck M: Toll-like receptors TLR4, TLR5 and TLR9 on gastric carcinoma cells: an implication for interaction with Helicobacter pylori. Int J Med Microbiol 295: 179-185, 2005.

25. Ilvesaro JM, Merrell MA, Swain TM, Davidson J, Zayzafoon M, Harris KW and Selander KS: Toll-like receptor-9 agonists stimulate prostate cancer invasion in vitro. Prostate 67: 774-781, 2007.

26. Ludwig L, Oswald F, Hoang-Vu C, Dralle H, Hildt E, Schmid RM and Karges W: Expression of the Grb2-related RET adapter protein Grap-2 in human medullary thyroid carcinoma. Cancer Lett 275: 194-197, 2009.

27. Yoneda K, Sugimoto K, Shiraki K, Tanaka J, Beppu T, Fuke H, Yamamoto N, Masuya M, Horie R, Uchida K and Takei Y: Dual topology of functional Toll-like receptor 3 expression in human hepatocellular carcinoma: differential signaling mechanisms of TLR3-induced NF- $\mathrm{KB}$ activation and apoptosis. Int J Oncol 33: 929-936, 2008.

28. Leifer CA, Kennedy MN, Mazzoni A, Lee C, Kruhlak MJ and Segal DM: TLR9 is localized in the endoplasmic reticulum prior to stimulation. J Immunol 173: 1179-1183, 2004.

29. Brinkmann MM, Spooner E, Hoebe K, Beutler B, Ploegh HL and Kim YM: The interaction between the ER membrane protein UNC93B and TLR3, 7 and 9 is crucial for TLR signaling. J Cell Biol 177: 265-275, 2007.

30. Kim YM, Brinkmann MM, Paquet ME and Ploegh HL: UNC93B1 delivers nucleotide-sensing toll-like receptors to endolysosomes. Nature 452: 234-238, 2008.

31. Ewald SE, Lee BL, Lau L, Wickliffe KE, Shi GP, Chapman HA and Barton GM: The ectodomain of Toll-like receptor 9 is cleaved to generate a functional receptor. Nature 456: 658-662, 2008.

32. Ren T, Xu L, Jiao S, Wang Y, Cai Y, Liang Y, Zhou Y, Zhou H and Wen Z: TLR9 signaling promotes tumor progression of human lung cancer cell in vivo. Pathol Oncol Res 15: 623-630, 2009.

33. Honda K, Yanai H, Mizutani T, Negishi H, Shimada N, Suzuki N, Ohba Y, Takaoka A, Yeh WC and Taniguchi T: Role of a transductional-transcriptional processor complex involving MyD88 and IRF-7 in Toll-like receptor signaling. Proc Natl Acad Sci USA 101: 15416-15421, 2004.

34. Kawai T, Sato S, Ishii KJ, Coban C, Hemmi H, Yamamoto M, Terai K, Matsuda M, Inoue J, Uematsu S, Takeuchi O and Akira S: Interferon-alpha induction through Toll-like receptors involves a direct interaction of IRF7 with MyD88 and TRAF6. Nat Immunol 5: 1061-1068, 2004.

35. Kawai T and Akira S: TLR signaling. Cell Death Differ 13: 816-825, 2006

36. Baldwin AS Jr: Series introduction: the transcription factor NF-кB and human disease. J Clin Invest 107: 3-6, 2001

37. Karin M, Cao Y, Greten FR and Li ZW: NF-kappaB in cancer: from innocent bystander to major culprit. Nat Rev Cancer 2: 301-310, 2002 .

38. Ghosh S and Karin M: Missing pieces in the NF-кB puzzle. Cell 109: S81-S96, 2002.

39. Ji P, Diederichs S, Wang W, Böing S, Metzger R, Schneider PM, Tidow N, Brandt B, Buerger H, Bulk E, Thomas M, Berdel WE, Serve $\mathrm{H}$ and Müller-Tidow C: MALAT-1, a novel non-coding RNA, and thymosin 34 predict metastasis and survival in earlystage non-small cell lung cancer. Oncogene 22: 8031-8041, 2003.

40. Lin R, Maeda S, Liu C, Karin M and Edgington TS: A large non-coding RNA is a marker for murine hepatocellular carcinomas and a spectrum of human carcinomas. Oncogene 26: 851-858, 2007

41. Luo JH, Ren B, Keryanov S, Tseng GC, Rao UN, Monga SP, Strom S, Demetris AJ, Nalesnik M, Yu YP, Ranganathan S and Michalopoulos GK: Transcriptomic and genomic analysis of human hepatocellular carcinomas and hepatoblastomas. Hepatology 44: 1012-1024, 2006.

42. Bateman NW, Tan D, Pestell RG, Black JD and Black AR: Intestinal tumor progression is associated with altered function of KLF5. J Biol Chem 279: 12093-12101, 2004.

43. Zhao J, Wu G, Bu F, Lu B, Liang A, Cao L, Tong X, Lu X, Wu M and Guo Y: Epigenetic silence of ankyrin-repeat-containing, SH3-domain-containing, and proline-rich-region-containing protein 1 (ASPP1) and ASPP2 genes promotes tumor growth in hepatitis B virus-positive hepatocellular carcinoma. Hepatology 51: $142-153,2010$. 